Artigo original

Hegemonia - Revista Eletrônica de Relações Internacionais do Centro Universitário Unieuro

ISSN: 1809-1261

UNIEURO, Brasília, número 7, 2011, pp. 73-119.

Recebido em: 15/11/2010

Revisado em: 23/11/2010

Aprovado em: 10/12/2010

\title{
O Brasil nas coalizões de geometria variável e os desafios da
}

\section{nova ordem global}

Aguiar, João Henrique Catraio Monteiro ${ }^{1}$

RESUMO: O presente artigo pretende investigar a coalizão entre o Brasil e outros países emergentes. Para tanto, será feita uma análise do panorama internacional na qual evoluem as relações. Ainda, enfocará os grupos que tem a presença brasileira: G-3, G-4, G-5, G20, BASIC, BRIC. O texto intenta demonstrar como esses grupos podem promover a aceleração do processo de mudança na ordem global, e para isso, eles agem de diferentes maneiras.

PALAVRAS-CHAVE: Política Externa Brasileira, Coalizões internacionais, Mudanças na ordem global, Países emergentes.

ABSTRACT: This article aims to investigate the coalition between Brazil and other emergent countries. In order to do so, there will be done an analysis of the international background in which evolves the relations. Further, it shall focus on the groups with the Brazilian presence: G-3, G-4 G-5, G-20, BASIC, BRIC. The paper pretend to demonstrate how these groups may foster the acceleration of the changing process in global order; and for that, they act on different ways.

KEY-WORDS: Brazilian Foreign Policy, International Coalitions, Changes in global order, Emergent Countries.

\footnotetext{
1 Mestrando em Relações Internacionais na Universidade Estadual do Rio de Janeiro. Professor de Sociologia e Ciências Sociais no Colégio Pedro II.
} 
Artigo original

Hegemonia - Revista Eletrônica de Relações Internacionais do Centro Universitário Unieuro

ISSN: 1809-1261

UNIEURO, Brasília, número 7, 2011, pp. 73-119.

\section{I ntrodução: os desafios da nova ordem global}

Em 1955, em Bandung, estava lançada a estratégia inicial de cooperação que não visava compactuar com a lógica "Oeste versus Leste", a essa etapa se juntou a possibilidade de iniciar uma Nova Ordem Econômica Internacional; e em meio a muitas crises e oportunidades surge uma nova etapa com o fim da Guerra Fria (ZORGBIBE, 1996). Os três retratos são pilares para entender o que será construído ao longo dos anos 2000', que se iniciam com o temor do bug do milênio e se encerram com a discussão sobre a "hecatombe de 2012". De lado os temores mais cômicos estão os temores mais trágicos, surgidos com a dispersão do terrorismo pelo globo. E pela fragilidade dos Estados Unidos da América, em 2001 com os atentados e em 2008 com a crise financeira. É nesse contexto que surgem novas iniciativas multilaterais e intergovernamentais, muitas de baixa institucionalidade, envolvendo o Brasil.

Coincidindo com uma mudança na sociedade internacional (BULL, 2002) está a reconfiguração do perfil da diplomacia brasileira. Compelida então por mudanças como as que estavam em pauta com a chegada de novos atores devido à democratização, ainda que a 
Artigo original

Hegemonia - Revista Eletrônica de Relações Internacionais do Centro Universitário Unieuro

ISSN: 1809-1261

UNIEURO, Brasília, número 7, 2011, pp. 73-119.

instituição diplomática tenha tradição consolidada (LIMA, 2000). O Brasil passa a ser, desde o início do século XXI, um Estado Logístico, que busca congregar as diversas forças sociais (empresários, trabalhadores, burocracias, etc.) em prol do desenvolvimento e projeção nacional (CERVO, 2008). Dentro dessa nova lógica estão incluídas as novas construções de blocos de poder internacionais que estarão criando condições de reformar a política mundial. A seguir não haverá uma análise da política externa dos emergentes e tampouco a política externa do Brasil será enfocada exaustivamente. $\mathrm{O}$ artigo se pretende enfocar nas pontes realizadas do Brasil com outros países que assumem crescentemente maior importância no sistema internacional.

\section{As coalizões de geometria variável do Brasil.}

O Brasil então começou a construir coalizões de geometria variável com parceiros diversos. A cada grupo formado, havia uma intenção que unia os países membros. Dentro dessas alianças podese encontrar a presença de parceiros estratégicos do país. Muitas vezes, para construir essas parcerias foi preciso recorrer à atuação de 
Artigo original

Hegemonia - Revista Eletrônica de Relações Internacionais do Centro Universitário Unieuro

ISSN: 1809-1261

UNIEURO, Brasília, número 7, 2011, pp. 73-119.

diplomacia cultural, na qual o país tem se empenhado desde muito tempo (LESSA, 2002). A análise da política cultural externa do país será explorada em outra oportunidade. Por hora, caberia entender como aumenta a importância dos acrônimos na formulação e prática da política externa brasileira. Ainda que o país tenha passado por uma crise de paradigmas desde a abertura democrática, se comparado com os paradigmas do globalismo e americanismo (PINHEIRO, 2004), ele manteve, em linhas gerais alguns consensos e algumas disputas. Surgem novas polaridades no Itamaraty, como entre os autonomistas e os institucionalistas pragmáticos (SARAIVA, 2010). Esse trabalho não tem em conta abordar todas as coalizões formadas pelo Brasil, mas somente algumas que tiveram mais impacto sob a batuta da corrente autonomista, notadamente, entre 2003 e 2010. São cruciais para essa época: BRIC, IBAS, G-20 financeiro, G-20 da OMC, G-4, BASIC. Destaco esses, pois dão um panorama multifacetário do multilateralismo executado pelo Brasil. A princípio, essas iniciativas são orientadas no sentido de mudar a ordem mundial, em vários aspectos.

A priori, pode-se entender como coligações que se formam em dois eixos: o pragmático e o ideológico. Ainda que esses eixos em 
Artigo original

Hegemonia - Revista Eletrônica de Relações Internacionais do Centro Universitário Unieuro

ISSN: 1809-1261

UNIEURO, Brasília, número 7, 2011, pp. 73-119.

termos filosóficos colidam, na prática eles se unem. Por um lado as nações buscam alcançar pragmaticamente objetivos específicos, delimitados pelos países que estão presentes nesses grupos; por outro lado é nítida a opção por alterar o panorama da cena internacional, vis-à-vis a formação de um bloco histórico antiunilateralismo. Pode-se pensar em uma iniciativa que visa ir contra um "multilateralismo acessório" que fora executado pela hiperpotência global (AMORIM, 2008). As raízes dessas organizações podem estar nas práticas de aproximação do Terceiro Mundo, dos Não-Alinhados e até mesmo da não-aceitação da globalização assimétrica, cujas benesses não atingem a integralidade do mundo. Outra influência que se pode apreender é a da lógica estruturalista de cooperação da periferia frente à indiferença ou exploração do centro. A fim de dar início à análise das coalizões brasileiras, optar-se-á pela investigação do G-3 ou IBAS. 
Artigo original

Hegemonia - Revista Eletrônica de Relações Internacionais do Centro Universitário Unieuro

ISSN: 1809-1261

UNIEURO, Brasília, número 7, 2011, pp. 73-119.

IBAS (Fórum Índia-Brasil-África do Sul) ou G-3 e a Cooperação Sul-Sul.

A criação de uma coalizão entre Índia, Brasil e África do Sul se relaciona com a importância que tem a relação Sul-Sul para o governo Lula. Formado em junho de 2003 através da Declaração de Brasília, o "Fórum de Diálogo IBAS" tem a missão de unir o Sul da América, da África e da Ásia. Para o grupo, faz-se necessária a defesa: da democracia, do direito internacional, da soberania, do desenvolvimento, segurança alimentar, educação, saúde, etc. São muitos os focos e eles estão agrupados dentro da iniciativa de se obter mais consenso em assuntos de importância. Através do Fundo IBAS consolidou-se a iniciativa de combate à fome e à pobreza, notadamente com uma cooperação trilateral presente em Haiti, Laos, Burundi, Guiné Bissau, etc.

Além disso, o licenciamento compulsório de fármacos foi algo buscado pelos integrantes, notadamente no caso do coquetel antiHIV/SIDA. Nesse ínterim, estava configurada a transferência de tecnologia e a cooperação internacional para a saúde, em um eixo que poderia abdicar da dependência de auxílios "vindos do Norte". 
Artigo original

Hegemonia - Revista Eletrônica de Relações Internacionais do Centro Universitário Unieuro

ISSN: 1809-1261

UNIEURO, Brasília, número 7, 2011, pp. 73-119.

Isso suscitou apoio de países do Sul, mobilização da sociedade civil em países do Norte, apoio de ONG's importantes (como o Médicin sans fronteirès), e apoio da ONU; e a aliança IBAS se consolidou como modelo de atuação Sul-Sul, em vias de construir propostas conjuntas na ONU, na OMC e em temas sensíveis (OLIVEIRA, 2005).

De acordo com Celso Amorim, em entrevista recente ${ }^{2}$, o IBAS é uma união de três grandes democracias, em três diferentes continentes, baseadas na noção de cooperação sul-sul que nasceu na ONU; com várias atuações diferentes, e que gera resultados práticos. Ainda, de acordo com o Ministro das Relações Exteriores dos governos Lula e Itamar Franco, a cooperação sul-sul seria uma nova forma de reforçar o multilateralismo. Assim, há certa dose de pragmatismo dentro da coalizão, principalmente se entendermos o mundo como sufocado pela ação dos EUA contra o terror, que faz do multilateralismo mera ilusão, não havendo multipolaridade (MI LLER, 2004). Portanto, a coalizão sul-sul não comporta somente um componente ideológico.

\footnotetext{
2 http://neccint. wordpress.com/2010/10/28/celso-amorim-fala-sobre-apolitica-externa-brasileira-bric-ibas-basic-conselho-de-seguranca-diplomacia-emuito-mas/
} 
Artigo original

Hegemonia - Revista Eletrônica de Relações Internacionais do Centro Universitário Unieuro

ISSN: 1809-1261

UNIEURO, Brasília, número 7, 2011, pp. 73-119.

Assim, entende-se que a aproximação em blocos é muitas vezes construída ao mesmo tempo com parcerias estratégicas com "países do sul", principalmente países emergentes extra-regionais (SARAIVA, 2007). É sob essa lógica que surgem as alianças entre o Brasil, Índia e África do Sul; num horizonte em que os países teriam uma maior participação na ordem mundial. A construção da ação coletiva, congregando potências médias com grande capacidade de no futuro emergir como incontestes potências; é algo que remete aos esforços que a diplomacia brasileira construiu como paradigma. Se hoje em dia há uma corrente nacionalista-autonomista no Itamaraty, ela tem raízes nas ações do Pragmatismo Responsável e Ecumênico, bem como nas diretrizes da Política Externa Independente. A autonomia buscada de forma pragmática é, então, a tônica dos atos.

Conforme Lula, em discurso de abertura de Cúpula do IBAS em 2006:

"O IBAS é muito mais que uma construção diplomática. É a expressão natural de identidades de visão sobre temas internacionais. É também uma manifestação concreta de objetivos compartilhados por Brasil, Índia e África do Sul. Somos democracias plenamente consolidadas, que dão exemplo de convivência harmônica entre as várias etnias e culturas que formam nossas sociedades. Somos economias emergentes, destinadas a ter presença internacional sempre 
Artigo original

Hegemonia - Revista Eletrônica de Relações Internacionais do Centro Universitário Unieuro

ISSN: 1809-1261

UNIEURO, Brasília, número 7, 2011, pp. 73-119.

mais relevante. Somos, também, países que ainda enfrentam o desafio de combater a pobreza extrema e lograr um desenvolvimento sustentável. (...) $O$ que queremos com o IBAS e outras iniciativas, é aproveitar melhor oportunidades de cooperação Sul-Sul antes inexploradas." (LULA apud BRASIL/MRE, 2007: 150/151)

\section{G-4 (Brasil, J apão, Alemanha e Índia) e a Reforma da ONU.}

A Índia faz parte também de outro vértice de atuação em bloco construída pelo país. Através de uma coalizão que envolve quatro grandes países que representam pontos estratégicos no globo, e visando maior representatividade no Conselho de Segurança, foi formado o G-4 (com Brasil, Índia, Alemanha e Japão) ${ }^{3}$. A ideia de ocupar posição de destaque na cena militar internacional, e ter prestígio no reduzido clube das potências militares internacionais, o Brasil buscou - em vão - uma cadeira no Conselho da Liga das Nações (GARCIA, 2000). A fim de conquistar esse (novo) assento na ONU, o país começa a atuar de várias formas. Uma delas é o

3 Essa é uma das áreas sensíveis em que se pode encontrar uma contrapartida. Com relação ao G-4 existe o bloco de oposição às quatro candidaturas que é o "Unidos pelo Consenso", o último congrega 40 países. 
Artigo original

Hegemonia - Revista Eletrônica de Relações Internacionais do Centro Universitário Unieuro

ISSN: 1809-1261

UNIEURO, Brasília, número 7, 2011, pp. 73-119.

argumento $^{4}$; que se subdivide, de acordo com João Vargas, em quatro: 1. "Argumento legitimador geral", em que a Reforma do Conselho seria benéfica a todos, pois o Conselho teria maior legitimidade; 2. "Argumento legitimador doméstico", que visa demonstrar a importância do Brasil conquistar esse assento, e é mais voltado ao público interno; 3. "Argumento credencial", no qual se demonstra porque o Brasil deveria ocupar um assento permanente; 4. "Argumento regional", no qual o país tenta convencer o seu entorno que sua presença no Conselho seria benéfica para a região (VARGAS, 2008).

A busca pelo assento tem sido uma constante, e está amparada na tradição que a diplomacia brasileira tem para si. Contrastando com isso estão as diferentes ênfases dadas por cada governo à política externa. Principalmente tendo em menta a diplomacia presidencial, o tema da segurança, tal como outros, como cultura, costumam ter enfoques bem diferentes. Vale lembrar também que outras iniciativas no campo da defesa também foram importantes para o país, como o

4 De acordo com J oão Vargas, o argumento pode ser usado em três sentidos: para persuadir o outro, para fortalecer a própria posição, para enfraquecer a posição do outro. Além disso, ele pode tanto servir para desígnios externos da política como pode ser uma força dentro do jogo político interno. 
Artigo original

Hegemonia - Revista Eletrônica de Relações Internacionais do Centro Universitário Unieuro

ISSN: 1809-1261

UNIEURO, Brasília, número 7, 2011, pp. 73-119.

Tratado Interamericano de Assistência Recíproca, e mais recentemente o Conselho de Defesa Sul-Americano.

Desde 1993 é discutida a reforma do CSNU. Faz sentido então a união em 2004 de Alemanha, Japão, Índia e Brasil no G-4, uma vez que eles contribuíram ativamente para as operações de paz e no financiamento do órgão; e o Brasil especificamente por poder ser representante tanto dos desenvolvidos como dos em desenvolvimento (GUEDES, 2009). Outros grupos reivindicaram outras reformas específicas no Conselho, e até mesmo grupos defenderam maior eficácia do ECOSOC. Mas em termos de reforma, o Brasil está mais ligado ao G-4 e às possíveis alterações que venha a acontecer no Conselho de Segurança. Conforme a Declaração do G-4 sobre a reforma do Conselho de Segurança da ONU:

"A reforma do Conselho de Segurança é o mais importante objetivo pendente entre aqueles adotados pelos Chefes de Estado e de Governo na Cúpula Mundial de 2005. (...) O G-4 crê firmemente que um Conselho de Segurança que reflita integralmente as atuais realidades políticas será mais representativo e, portanto, mais legítimo e eficaz. (...) o G-4 mantém-se comprometido com uma reforma significativa com base na expansão das categorias permanente e não-permanente, com a inclusão, em ambas, de países desenvolvidos e em desenvolvimento, e na adoção 
Artigo original

Hegemonia - Revista Eletrônica de Relações Internacionais do Centro Universitário Unieuro

ISSN: 1809-1261

UNIEURO, Brasília, número 7, 2011, pp. 73-119.

de métodos de trabalho aperfeiçoados." (G-4 apud BRASIL/MRE, 2007: 201).

\section{G-20 financeiro, G-20 comercial e G-5.}

O Brasil conviveu com mudanças estruturais profundas, de 20 anos atrás até hoje, foram destruídas as ideologias coletivistas, surgiram o neoliberalismo e suas mazelas, que foram superadas; e posteriormente se colocaram grandes crises: financeira, militar, energética, política, ambiental ${ }^{5}$. Por conta disso, o país buscou encarar grandes desafios, tais como a articulação regional, a articulação interna, a defesa de normas, a propagação do desenvolvimento. Conforme se colocavam essas questões em discurso do Secretário-Geral do Itamaraty, também eram colocadas questões importantes pelo Ministro das Relações Exteriores, Celso Amorim. Seria preciso então lutar pelo desenvolvimento, pela

5 Para entender melhor esse longo processo de mudanças ver o discurso de Samuel Pinheiro Guimarães na abertura da III Conferência de Política Externa e Política Internacional "O Brasil no mundo que vem aí", de 2008. No discurso ele delineia o longo percurso passado pelo país e as questões atuais mais candentes. 
Artigo original

Hegemonia - Revista Eletrônica de Relações Internacionais do Centro Universitário Unieuro

ISSN: 1809-1261

UNIEURO, Brasília, número 7, 2011, pp. 73-119.

igualdade entre as nações, pela democratização dos órgãos internacionais; e isso envolveria uma política externa calcada no multilateralismo (AMORIM, 2007).

Todavia, para entender esse processo é preciso se faz necessário compreender as raízes históricas dessa evolução da política externa. Nos anos 1940, com muitos países afetados pela crise dos anos 1930, são lançadas as bases da atual cooperação internacional econômica, através do surgimento do General Agreement on Tariffs and Trade. 0 GATT 47 foi o local onde várias iniciativas surgiram, como por exemplo o Grupo de Cairns, que visava o livre-comércio agrícola. Também surge, no período que antecede a Organização Mundial de Comércio, a UNCTAD, voltada para o desenvolvimento; e a CEPAL, com reflexões sobre a deterioração dos termos de troca e a substituição de importações, que influenciarão a América Latina.

Como o sistema internacional condiciona a existência de regimes internacionais, e não havia consenso sobre o GATT, ele não evoluiu. Vale lembrar que o Brasil foi um dos 23 países a participar da criação do órgão. Pretendia-se retirar barreiras não-alfandegárias e reduzir tarifas a fim de promover o comércio internacional. Mas como isso seria possível uma vez que a parte socialista do mundo não ensejava 
Artigo original

Hegemonia - Revista Eletrônica de Relações Internacionais do Centro Universitário Unieuro

ISSN: 1809-1261

UNIEURO, Brasília, número 7, 2011, pp. 73-119.

o livre-comércio com países capitalistas? A iniciativa contava ainda com outro empecilho, que era o fato de os EUA prescindirem do GATT para estabelecer as suas relações comerciais. Os países que necessitavam de impulso maior nas suas economias acreditavam mais no potencial de ajudas econômicas (como o Plano Marshall) que na questão comercial.

A evolução da Rodada Uruguai (que deu origem à OMC), no GATT, se deu ao mesmo tempo em que ocorria: a abertura políticoeconômica da URSS, declínio dos EUA, a ascensão de Japão e Europa, a entrada na agenda de novos temas (investimento, propriedade intelectual, questões ambientais, desequilíbrios sociais) (SATO, 2006). Desde essa época de surgimento da OMC o país tinha estabilidade econômica, era um país industrializado e com um forte potencial no comércio agrícola. Desde muito tempo nações em desenvolvimento com potencial agrícola tinham dificuldades no comércio com a União Européia (devido à Política Agrícola Comum) e com os EUA (devido às Farm Bills). O Brasil, devido à sua capacidade nas exportações de produtos agrícolas e primários, estava nesse meio. Participou do Grupo de Cairns, e de várias iniciativas para defender seus interesses. Porém, as negociações começam a ter mais 
Artigo original

Hegemonia - Revista Eletrônica de Relações Internacionais do Centro Universitário Unieuro

ISSN: 1809-1261

UNIEURO, Brasília, número 7, 2011, pp. 73-119.

densidade desde a criação em 2003 do G-20 na OMC, em Cancún.

Conforme explicitado por Celso Amorim, em Palestra feita em Lisboa:

"O G-20, criado no calor da fracassada reunião de 2003 em Cancún, mudou o padrão das negociações na OMC. (...) A Rodada nunca teria avançado tanto, sobretudo em temas de interesse dos países em desenvolvimento, se não fosse a mobilização gerada pelo G-20. (...)Uma das características do G-20 é o fato de incluir países muito diferentes (...)O ponto comum é que todos são profundamente afetados pelos subsídios distorcivos e elas políticas protecionistas dos países ricos. (...) A ação do G-20 tem sido propositiva, tecnicamente bem amparada e voltada para resultados. O acordo que for alcançado na Rodada de Doha, em matéria de agricultura, terá sido em grande parte obra do G-20. A articulação de países do Sul contribui para a estabilidade global e para a adoção de regras sistêmicas multilateralmente acordadas." (AMORIM apud BRASIL/MRE, 2010: 175).

A construção de uma agenda comercial afirmativa com diversificação de parceria foi estimulada com essa iniciativa; uma vez que esse grupo congrega $70 \%$ da população rural do mundo, tem interlocução com o Grupo de Cairns e G-90, com foco no desenvolvimento, segurança alimentar, garantia às populações aos meios de subsistência, eliminação de subsídios (VIZENTINI, 2006). 
Artigo original

Hegemonia - Revista Eletrônica de Relações Internacionais do Centro Universitário Unieuro

ISSN: 1809-1261

UNIEURO, Brasília, número 7, 2011, pp. 73-119.

Contando com algum grau de sorte, o país encontrou-se em um contexto internacional no qual os países desenvolvidos estavam em crise e os países em desenvolvimento começavam a se agrupar em um bloco. A crise chegou aos Estados Unidos da América através da crise dos subprimes, e posteriormente com a quebra do Lehman Brothers, o que fez com que o novo presidente, democrata, tivesse que implementar um pacote econômico de recuperação, que agora intervinha na economia, com políticas anti-cíclicas e programas sociais (TAVARES, 2008). Colocava-se então uma reação à financeirização da riqueza. Muitos países começam a se posicionar contra a especulação financeira desenfreada e se colocam a favor do controle estatal, entre esses países estão o Brasil, a França, os EUA, entre outros. Se a iniciativa do G-20 financeiro existia desde 1999, ela terá maior influência sobre a economia mundial desde a crise profunda que atingiu o epicentro do capitalismo mundial. Principalmente se pensarmos que crescem as soluções multilaterais para os problemas globais. Conforme Celso Amorim, na Aula Inaugural do Curso de Relações Internacionais da UFRJ :

“O Brasil, que presidiu o G-20 financeiro em 2008, faz parte da tróica do grupo. Na reunião em Londres, o Presidente Lula defendeu uma maior 
Artigo original

Hegemonia - Revista Eletrônica de Relações Internacionais do Centro Universitário Unieuro

ISSN: 1809-1261

UNIEURO, Brasília, número 7, 2011, pp. 73-119.

participação dos países em desenvolvimento na arquitetura internacional. Advogou a criação de mecanismos de regulação da economia internacional. E convocou os líderes mundiais a caminharem em direção à conclusão da Rodada Doha. O encontro do G-20 em Londres foi importante para reconhecimento da importância da recapitalização das instituições internacionais de empréstimo, da necessidade de regulação do sistema financeiro internacional e da inclusão dos países em desenvolvimento no processo decisório da economia global. (...) São necessárias soluções multilaterais para os problemas globais. 0 multilateralismo é o canal mais legítimo para coordenar a crise no plano internacional. Os encontros do G-20 em Washington e em Londres são sinais dessa mudança no processo decisório internacional. O G-20 financeiro é um passo importante na multilateralização do tratamento das questões econômicas globais." (AMORIM apud BRASIL/MRE, 2010: 179).

Anunciar-se-ia o crepúsculo da ordem econômica mundial cujos ditames eram norte-americanos? É cedo para dizer. A verdade é que o bloco possui $85 \%$ do PIB mundial, e nele estão disseminadas as sementes da mudança. Já estão assinalados nesse órgão, bem como no Fórum Econômico Mundial a iniciativa de reforma das instituições de Bretton Woods; principalmente envolvendo alterações no FMI, BIRD, ONU. Finalizando o tema, já não mais o G-8 se reúne sozinho. Desde 2007 há a incorporação dos 8 países mais ricos das 5 maiores 
Artigo original

Hegemonia - Revista Eletrônica de Relações Internacionais do Centro Universitário Unieuro

ISSN: 1809-1261

UNIEURO, Brasília, número 7, 2011, pp. 73-119.

economias emergentes: China, México, África do Sul, Índia e Brasil. O Brasil se coloca então, a favor da reforma das instâncias do G-8 com vias de que com a entrada dos emergentes aumente a representatividade. Conforme Amorim, na Conferência Anual dos Embaixadores Franceses:

“Na política, seja nacional seja internacional, uma entidade não pode prescindir nem de legitimidade nem de eficácia. Hoje, esses dois elementos faltam ao G-8. A respeito de sua legitimidade, sempre houve dúvidas, uma vez que o G-8 nunca superou a condição de clube de ricos, seleto e pouco representativo. Quanto à eficácia, o grupo tampouco demonstra tê-la, uma vez que os grandes países em desenvolvimento, indispensáveis para o funcionamento da ordem internacional dos nossos dias, não estão ali incluídos. O grupo poderá, no entanto, se redefinir, na medida em que o processo de incorporação dos países emergentes - o G-5 (Brasil, África do Sul, China, Índia e México), com a adição do Egito e, eventualmente, de outros países - caminhe no sentido da constituição de um conjunto mais inclusivo e diversificado. De fato, essa "nova geografia internacional" foi antecipada pelo Presidente Lula desde seu primeiro mandato." (AMORIM apud BRASIL/MRE, 2010: 180)

Ainda que o fórum seja chamado de G8+5 existe a proposta por parte de Nicolas Sarkosy de incorporar os cinco emergentes ao grupo dos países mais ricos do mundo. A projeção desses países 
Artigo original

Hegemonia - Revista Eletrônica de Relações Internacionais do Centro Universitário Unieuro

ISSN: 1809-1261

UNIEURO, Brasília, número 7, 2011, pp. 73-119.

emergentes é, portanto, reconhecida entre os países mais influentes na economia mundial. E o Brasil, dessa forma, torna-se um global player.

\section{BASIC (Brasil, África do Sul, Índia e China) e a mudança climática.}

O sociólogo Giddens aponta para uma modernização que estaria despertando conseqüências nefastas ao meio-ambiente, principalmente através do industrialismo, que afeta profundamente a natureza; além disso, ocorrem desencaixes no tempo e no espaço que obrigam às sociedades a se adequar a novas dimensões de risco (GIDDENS, 1991). Teóricos como James Lovelock e Vandana Shiva também tiveram grande impulso e influíram muitos movimentos sociais. Se no âmbito intergovernamental existe a ação do PNUMA, da ONU ${ }^{6}$ no âmbito não-governamental destacam-se WWF, Greenpeace, PETA, entre outras. Outra importante contribuição foi a da mídia ${ }^{7}$, que internacionalmente impulsiona a discussão sobre o

\footnotetext{
6 Também no âmbito da ONU destaca-se 2010 como "O ano da biodiversidade" e também "Ano Internacional para a Aproximação das Culturas".

7 Sobre o BASIC também houve repercussão na imprensa, mas prioritariamente nos órgãos de comunicação que desenvolvem suas atividades dentro dos países do grupo.
} 
Artigo original

Hegemonia - Revista Eletrônica de Relações Internacionais do Centro Universitário Unieuro

ISSN: 1809-1261

UNIEURO, Brasília, número 7, 2011, pp. 73-119.

tema. E no âmbito da propaganda sobre o assunto destacaram-se recente os filmes: "The Corporation", "Home" e "An inconvenient truth". Essa trinca cinematográfica despertou muitas pessoas para questões relativas às mudanças na biosfera. As conferências climáticas de Estocolmo em 1972, Rio de Janeiro em 1992 e J ohannesburgo em 2002 também foram incisivas para tal. Tem sido um dos pontos de tensão mundial incisivos, principalmente nas Conferências das Partes do Acordo Quadro das Nações Unidas sobre Mudança Climática. Discute-se o comércio de créditos de carbono e a compensação pela redução desmatamento.

Talvez a mais jovem das coalizões do Brasil, formada em 2009, a BASIC (Brasil, África do Sul, Índia e China) tem como predisposição estimular as nações ricas a apoiarem as nações em desenvolvimento para alcançar metas ambientais; além disso, o grupo provê auxílio técnico e auxílio em formação de pessoal e científico. O grupo tentou incluir uma cadeira das negociações para um representante do G-77. Dessa forma, é reforçada uma posição "do Sul", que é diferente da posição que tem os Estados Unidos da América (que não assinaram o Protocolo de Kyoto); e também diferente da meta de redução de emissões proposta pela União Européia. Forma-se então um bloco 
Artigo original

Hegemonia - Revista Eletrônica de Relações Internacionais do Centro Universitário Unieuro

ISSN: 1809-1261

UNIEURO, Brasília, número 7, 2011, pp. 73-119.

interregional, com características de baixa institucionalidade, construído sob a égide de um Fórum de criação de consenso para negociações ambientais. Com relação ao BASIC vê-se uma aproximação da ideia de desenvolvimento e atuação sobre as mudanças climáticas. Além disso, as iniciativas de desenvolvimento sustentável ficam mais ligadas às saídas governamentais e mantendo a soberania de casa nação.

Vale lembrar que esse grupo está inscrito na lógica de afirmar também posições do Sul como importantes, e de contraposição ao Norte (principalmente os países mais ricos). Todavia, destaca-se a posição de um país desenvolvido: França; que apoiou o país na iniciativa da Conferência em 2012 sobre o desenvolvimento sustentável (Rio+20). Ambos os países atuaram em prol da luta contra o desmatamento e a degradação ambiental. Esses temas tendem a ser discutidos no âmbito do BASIC.

\section{BRIC e a possibilidade de coalizões "emergente-emergente".}

O sociólogo Thomas K. Merton cunhou o termo "profecia autorealizável" através de seus estudos com uma sociologia de matriz 
Artigo original

Hegemonia - Revista Eletrônica de Relações Internacionais do Centro Universitário Unieuro

ISSN: 1809-1261

UNIEURO, Brasília, número 7, 2011, pp. 73-119.

weberiana, descrevendo um prognóstico que, ao se tornar crença, provoca a sua concretização. Ainda que esteja em outro campo do conhecimento, ela é perfeitamente aplicável a este grupo. Uma vez que após o artigo de Jim O’ Neill da Goldman Sachs de 2001, em que o termo BRIC foi inventado, passou-se a levar em consideração a possibilidade dessa aliança estratégica. Especulava-se que Brasil, Índia, China e Rússia juntos poderiam ultrapassar a capacidade econômica do G-8 (Grupo dos países mais ricos) em um futuro próximo. Ainda que essa futurologia não tenha caído nas graças dos países indicados desde o início, ela foi contemplada como algo possível. Assim, a profecia de união entre eles acabou por tornar-se realidade. De todas as aproximações abordadas nesse texto, essa é a que talvez seja mais impactante no longo prazo e a que mais pode oferecer chaves para mudanças no plano internacionais, se conduzida com sapiência. Pode-se ressaltar a heterogeneidade do grupo, que, tem em comum, entre outras coisas, o fato de ser uma premonição de economistas que ainda está para se confirmar no futuro.

A inserção econômica internacional é variada: A Rússia exporta matéria-prima energética; o Brasil exporta commodities alimentícias e minerais; a Índia desenvolve tecnologias; a China cresce com 
Artigo original

Hegemonia - Revista Eletrônica de Relações Internacionais do Centro Universitário Unieuro

ISSN: 1809-1261

UNIEURO, Brasília, número 7, 2011, pp. 73-119.

produtos de consumo de massa e um grande mercado interno. Índia e Brasil apresentam uma política mais democrática; porém Rússia e China têm, ainda, características autoritárias. Além disso, esse agrupamento não leva em consideração a diferença entre os tratamentos que esses países dão para a política cambial, comercial, de investimento estrangeiro, e suas relações com as instituições internacionais econômicas. Portanto, pode-se, conforme Botafogo Gonçalves (2009) entender esse grupo como repleto de paradoxos: É grupo, mas não tem uma agenda comum convergente, não tem posição geográfica comum, não tem condição político-econômica comum. Portanto, é difícil encaixar eles em uma categoria de "Norte" ou de "Sul" e ainda que sejam emergentes, eles possuem diferenças no tipo de ascensão que passam no sistema internacional. Enquanto um membro tem uma ascensão (China), outro se reafirma (Rússia), enquanto outros surgem como emergentes (Índia e Brasil); e para completar esse quadro as potencialidades de cada um são diversas, com formações sócio-culturais que se distinguem radicalmente umas das outras (ALMEIDA, 2009).

A Índia mistura a longa tradição hindu de castas e demais crenças arraigadas nas mentalidades locais com 0 desenvolvimento 
Artigo original

Hegemonia - Revista Eletrônica de Relações Internacionais do Centro Universitário Unieuro

ISSN: 1809-1261

UNIEURO, Brasília, número 7, 2011, pp. 73-119.

tecnológico e científico; com uma indústria cinematográfica poderosa, destacando-se a produção de "Bollywood". Os indianos têm um sistema parlamentarista multipartidário, sendo a maior democracia do mundo. Sua história é muito longa e - tal como a das Dinastias chinesas, ou do Império russo - é marcada por muitas disputas no território que se consolidou como majoritariamente hindu, apesar das invasões islâmica, mongol e a inglesa. Talvez seja o país, dos BRIC, com maior diversidade cultural.

A China tem grande produção industrial, produz bens de consumo e bens de capital, com orientação socialista que relê o maoísmo através do convívio entre Partido Comunista Chinês e relações intensas com EUA e com o capital financeiro e estrangeiro nas Zonas Econômicas Especiais. Sendo uma república socialista unipartidária, confronta-se constantemente com insatisfações por segmentos da população; também insatisfeitos com violações aos direitos humanos e à liberdade de imprensa. Os chineses convivem com a possibilidade de separatismo do Tibete. Apesar disso, é um país de poderio militar e econômico que pode tornar-se o hegemônico nos próximos anos. E tem uma maior homogeneidade cultural se comparado com os outros três países. 
Artigo original

Hegemonia - Revista Eletrônica de Relações Internacionais do Centro Universitário Unieuro

ISSN: 1809-1261

UNIEURO, Brasília, número 7, 2011, pp. 73-119.

A Rússia acumula uma história longa com influência das experiências marcantes do Império Russo e da União Soviética. Em ambos os casos, os russos tiveram ímpetos para unir os povos eslavos e para exercer influência maior sobre a Ásia. Tal como a China é membro permanente do Conselho de Segurança das Nações Unidas. Tem grande contingente de armas nucleares. Sendo talvez, o que esteja no maior dilema entre confrontar com os EUA pela hegemonia mundial ou construir no entorno maiores condições de segurança. A Rússia é uma república semipresidencialista.

Cada um desses três países tem uma forma muito específica de modelo civilizacional, de evolução cultural, de perfil político e de condução estatal. Mas parecem ter se consolidado enquanto nações através de um longo processo. O processo de construção nacional do Brasil, se comparado com o acumulado histórico dos outros três é deveras recente. Antes de 1500 existiam os nativos do país, porém a chegada dos colonizadores portugueses fez com que essa formação político-econômico-cultural prévia se transformasse em uma colônia. Durante 300 anos foi uma colônia portuguesa, e depois virou sede da Metrópole (entre 1808 e 1822). Foi depois um Império, uma monarquia parlamentar; e em seguida uma república. Essa curta 
Artigo original

Hegemonia - Revista Eletrônica de Relações Internacionais do Centro Universitário Unieuro

ISSN: 1809-1261

UNIEURO, Brasília, número 7, 2011, pp. 73-119.

trajetória, se comparada com a longa história dos outros três países citados, inclui um processo denso de construção de uma pluralidade cultural e étnica. Além disso, tem relativa tranqüilidade com sua vizinhança (o que não se verifica com os outros países).

O Brasil então desenvolveu um modelo econômico, cultural, político, demográfico, e etc., que é muito mais ocidental que os outros países citados. O que faz com que ele tenha relações de maior densidade ou dependência com o "mundo ocidental" do mundo, diferente de Índia e China que teriam maiores relações com o "mundo oriental" e da Rússia, que eventualmente pode ser considerada uma ponte entre os dois mundos. Podemos, porém, ver que historicamente os BRIC não tiveram profundas relações entre si, e essa conexão vem sendo construída somente recentemente (GONÇALVES, 2010). De acordo com Gonçalves (2010), o quadro futuro ainda sugere muita negociação, confrontação ou cooperação, mas certamente poderia ser mais favorável para todos se houvesse maior inovação.

Vejamos então as semelhanças entre os BRIC. A princípio são países de grandes dimensões, com enorme contingente populacional, com problemas com fronteiras ou nacionalismos (à exceção do 
Artigo original

Hegemonia - Revista Eletrônica de Relações Internacionais do Centro Universitário Unieuro

ISSN: 1809-1261

UNIEURO, Brasília, número 7, 2011, pp. 73-119.

Brasil), com problemas de desigualdade social; tendo também potencial econômico a ser explorado (cada um de uma forma diferente). Especula-se que esse grupo junto ultrapassará o Produto Interno Bruto do G-7 por volta de 2035, e a China será então a maior potência. É evidente que esse panorama suscita questões candentes, conforme Paulo Roberto de Almeida:

"A experiência do passado - aliás, ainda recente em torno de algumas dessas escolhas e sobre as tentativas de impô-las, de modo autoritário, a sociedades inteiras, não nos traz ensinamentos muito otimistas sobre algumas das soluções propostas por desafiantes radicais do status quo. Não é preciso rememorar a história terrível da Alemanha nazista e do Japão militarista para contestar que países emergentes podem ser competidores apressados, aptos a contestar, pela violência em alguns casos, o poder estabelecido de hegemons mais antigos. A lição, em todo caso, de ter sido aprendida. Esperemos que desta vez seja diferente." (ALMEIDA, 2009: 65).

Portanto, para evitar esse cenário de conflitos advindos da enorme diversidade é preciso desenvolver a tolerância cultural, 
Artigo original

Hegemonia - Revista Eletrônica de Relações Internacionais do Centro Universitário Unieuro

ISSN: 1809-1261

UNIEURO, Brasília, número 7, 2011, pp. 73-119.

religiosa e racial; e construir uma agenda comum para a indústria, a agricultura, a tecnologia, etc. (GONÇALVES, 2009).

O Brasil parte, vale lembrar, de uma tradição corporativa forte com formação de seu corpo de diplomatas em atmosfera de excelência. A linha de continuidade convive então com novas questões, como a politização da política externa, e a formação de grupos com afinidades partidárias no interior do Ministério (LIMA, 2009). Nos tempos atuais, junto com as alianças estratégicas, o Brasil usou muito o Soft Power para poder conquistar mais autonomia. Sendo consensual que o país deveria conquistar maior espaço, não é consensual como poderia ser feito isso. Uma das ferramentas foi justamente a formação de coalizões de geometria variável. O país então se afirma como uma "potência regional", vinculada a sua capacidade de administrar a estabilidade na região sul-americana e levando adiante o processo de integração regional; e por outro lado, o país se coloca como país intermediário, entre fortes e fracos, e maior meio de conquista desse status é através das relações Sul-Sul (HIRST, LIMA; 2009).

Apesar de o Brasil ser o país com o menor poder de compra entre os BRIC, é o que mais tem diminuído as desigualdades (ARBIX, 
Artigo original

Hegemonia - Revista Eletrônica de Relações Internacionais do Centro Universitário Unieuro

ISSN: 1809-1261

UNIEURO, Brasília, número 7, 2011, pp. 73-119.

2009), o que se liga com seus anseios de ascensão. Esse dado, porém, camufla um perfil de economia internacional que foi desenvolvido ao longo do governo Lula. Se por um lado combateu-se a miséria extrema e as assimetrias sociais com programas de assistência social de eficácia reconhecida, tal como o programa "Bolsa Família", por outro lado, uma parte do grande capital brasileiro se beneficiou enormemente. Desde 1990 alguns fatores influenciam o processo decisório da política externa brasileira - fim da Guerra Fria, globalização, desestatização, abertura econômica. Desde então, pode-se dividir a política externa em três momentos: 1. Abertura comercial e Mercosul, com estabilização monetária e controle da inflação 2. Regionalização com abertura, com investimento estrangeiro direto e privatizações, 3. Ativismo nacionalista, com incentivo ao comércio exterior, com grande incentivo às grandes corporações (OLIVEIRA, PFEIFER; 2006). A época áurea do desenvolvimento das alianças estratégicas, com o governo Lula, foi também de grande incentivo, através do ativismo nacionalista, do agronegócio e das grandes corporações. A projeção internacional do país poderia crescer com uma ação em parceria do público com o privado, estimulando a competitividade e a internacionalização. Nesse 
Artigo original

Hegemonia - Revista Eletrônica de Relações Internacionais do Centro Universitário Unieuro

ISSN: 1809-1261

UNIEURO, Brasília, número 7, 2011, pp. 73-119.

sentido, empresas realizaram fusões, abriram filiais, estabeleceram cooperação, e outros atos e conseguiram conquistar espaços maiores no exterior, destacam-se entre as internacionalizadas: Itaú, Ambev, Odebrecht, Petrobrás, Gol, Vale do Rio Doce, Gerdau, CSN, Votorantim, etc. (GREGORY, 2009).

Porém, o país precisa, ainda, rever sua logística de modo a potencializar o escoamento das exportações, a melhorar a condição de vida da população, etc.; e deve passar a usar fontes energéticas renováveis (LESSA et al, 2010).

\section{Conclusão: dos acrônimos às ações globais.}

Existem, de fato, novas orientações que surgem com a chegada de Luis Inácio Lula da Silva ao poder no Brasil. Elas podem ser entendidas de várias formas diferentes. A luta por maior equilíbrio no sistema internacional, com menor assimetria, faz com que surja a autonomia pela diversificação (CEPALUNI, VIGEVANI; 2007). Com isso, há um aumento do número de parcerias, que tem diferentes qualidades, desde a regional, passando pela coalizão Sul-Sul, até os emergentes e as potências mundiais. As negociações internacionais 
Artigo original

Hegemonia - Revista Eletrônica de Relações Internacionais do Centro Universitário Unieuro

ISSN: 1809-1261

UNIEURO, Brasília, número 7, 2011, pp. 73-119.

contam com o protagonismo do Brasil no sentido de reforçar o universalismo e o desenvolvimento. Para Vigevani e Cepaluni (2007), houve, por conta disso, maior aproximação com emergentes, sulamericanos e com africanos. Grupos que compõem os blocos descritos.

Sob outra perspectiva, o país, seguindo a tradição globalmultilateral, conjugaria duas estratégias: a horizontal e a vertical (PECEQUILO, 2008). O Brasil passou então a construir suas relações bilaterais ao mesmo tempo em que se afirmava como global player and trader. Tanto o eixo bilateral quanto o eixo multilateral eram utilizados no sentido de ampliar o poder de barganha do país. Porém, se comparado com outros países, o Brasil não tem tanta margem de manobra quanto seus companheiros da Eurásia; ficando sobre a área de influência norte-americana. As forças somadas com os grandes países periféricos se circunscrevem então na lógica Sul-Sul, de herança terceiro-mundista. Somando eixos horizontais e verticais estão os anseios de mudança das organizações internacionais, que são canalizados através dos grupos, com geometria variável. Esse quadro de alianças se conjuga com uma janela de oportunidades. 
Artigo original

Hegemonia - Revista Eletrônica de Relações Internacionais do Centro Universitário Unieuro

ISSN: 1809-1261

UNIEURO, Brasília, número 7, 2011, pp. 73-119.

Vê-se atualmente a atuação conjunta da Diplomacia Presidencial, com discursos importantes por parte de Lula, e uma Diplomacia de Cúpula, delineada através das alianças estratégicas (BARNABÉ, 2010). Essa pluralidade de alianças que existe no exterior faz parte também de uma ampla coalizão exercida no nível interno, notadamente através do Estado Logístico que se constrói (CERVO, 2008). Esses condicionamentos internos e externos fazem com que o país selecione determinados parceiros.

Curiosamente alguns países são recorrentes nas alianças que o Brasil tem traçado: Rússia, China, Índia, África do Sul, França, Alemanha, Japão, etc. Porém, os quatro primeiros são mais recorrentes; provavelmente porque eles resguardam algumas simetrias com o país. Essas, por sua vez, não impedem que surjam coalizões diversas, de objetivos variados, que guiam esses parceiros estratégicos. A formação de blocos de múltiplos objetivos é importante para potencializar decisões que muitas vezes são tomadas somente por um país.

Ainda que essas coalizões sejam de fato significativas para o sistema internacional, elas não são as únicas que devem ser levadas em conta. Recentemente, movimentos sociais da internet 
Artigo original

Hegemonia - Revista Eletrônica de Relações Internacionais do Centro Universitário Unieuro

ISSN: 1809-1261

UNIEURO, Brasília, número 7, 2011, pp. 73-119.

(ciberativismo) tiveram significativa importância na história da política estadunidense. Por um lado, uma organização que auxiliou o governo e, por outro lado, uma organização que atacou o governo. Amparados no direito a liberdade de expressão, garantida por lei, o movimento do WikiLeaks passou a divulgar informações referentes às guerras levadas adiante pelos Estados Unidos. O grupo Wiki tem tentado construir uma espécie de inteligência coletiva (LÉVY, 1999), calcada em fontes que se mantém sob segredo. Em contrapartida, encontra-se a ação de MoveOn.Org; que auxiliou as campanhas presidenciais de Barack Obama em 2008. O ciber-ativismo tem crescido e é uma força transnacional. Da mesma forma, a ação em volta do Fórum Social Mundial e a proposta do altermundialismo são construídos a partir de redes transnacionais de contestação (MILANI, 2007). Seria a conjunção de forças transnacionais e de forças estatais possível? Será que é necessária? São questões que o tempo responderá. Por ora, cabe dizer que a política mundial não é simples, e que nada está garantido no futuro. Quanto ao Brasil, pode-se especular que as coalizões internacionais despertam pelo menos três interpretações, assinaladas a seguir. 
Artigo original

Hegemonia - Revista Eletrônica de Relações Internacionais do Centro Universitário Unieuro

ISSN: 1809-1261

UNIEURO, Brasília, número 7, 2011, pp. 73-119.

1.1. Ação global dos emergentes: contra-hegemonia.

Certos pensadores podem considerar as alianças estratégicas firmadas como o início de uma formação de um bloco histórico contra-hegemônico com ações globais. Tendo em mente que os países do Norte e especificamente os Estados Unidos da América detêm a hegemonia das Relações Internacionais, então a cooperação Sul-Sul, - consubstanciada através de IBAS, G-20 comercial, BASIC, - seria uma afronta ao poder estabelecido. Gill e Law Os autores falam sobre o bloco histórico como dizendo respeito:

“(...) à congruência histórica entre forças materiais, instituições e ideologias ou, de modo geral, a uma aliança entre diferentes forças de classe. Por conseguinte, o bloco histórico era o vínculo "orgânico" entre o "político" e a "sociedade civil", uma fusão de capacidades materiais, institucionais, intersubjetivas, teóricas e ideológicas (...) Um bloco bem sucedido era politicamente organizado em torno de um conjunto de ideias hegemônicas que davam alguma coerência e direção estratégicas a seus elementos constituintes." (Gill, Law; 2007, pg. 158) 
Artigo original

Hegemonia - Revista Eletrônica de Relações Internacionais do Centro Universitário Unieuro

ISSN: 1809-1261

UNIEURO, Brasília, número 7, 2011, pp. 73-119.

Assim sendo, se essas alianças estratégicas conquistarem o apoio dos movimentos sociais, então elas ganharão força para mexer nas estruturas do capitalismo em seu centro mais dinâmico. Assim, materialmente existiria o desenvolvimento de países até então situados na periferia do sistema econômico. E ideologicamente eles estariam coesos sob o panorama de uma união internacional do sul. Sob essa perspectiva já se poderia considerar como possível o declínio do poderio ianque, devido a uma crise sistêmica do capitalismo global; e seria um momento oportuno para o surgimento de um "novo meridionalismo" congregando elementos diversos que poderiam construir uma resposta interregional à globalização e à hegemonia (MIHAILOVIC, 2010).

1.2. Os acrônimos: a racionalidade e os grupos de interesse.

Sob outra perspectiva, esses grupos seriam acionados por motivos realistas. Estando em uma situação onde há uma potência maior que pode se sobrepor, restam algumas opções: 1. Bandwagoning, 2. Hedging, 3. Balancing, 4. Barganha. Em português poderíamos 
Artigo original

Hegemonia - Revista Eletrônica de Relações Internacionais do Centro Universitário Unieuro

ISSN: 1809-1261

UNIEURO, Brasília, número 7, 2011, pp. 73-119.

traduzir essas opções da seguinte forma: 1. O país "aceita" o poder maior; 2. O país evita maiores riscos advindos do confronto com o poder maior; 3. O país se junta com outros países de menor potência para enfrentar o poder maior; 4. O país negocia trocar seu apoio pelo poder maior, em caso de o segundo ceder algo ao primeiro. Todas essas características podem ser encontradas no caso da formação de grupos nas relações internacionais.

Além disso, mais que por motivos ideológicos, as alianças internacionais refletem os interesses internos às burocracias estatais, conforme presente no modelo de política burocrática de Graham Allisson. Portanto, a política externa é formulada através de um processo decisório. E este passa pelas disputas de poder internas a maquina do estado. As lutas dentro do aparato estatal refletem também os interesses pessoais, que muitas vezes se sobrepõem à racionalidade exigida do corpo burocrático. Portanto, alianças internacionais surgem desde o ponto de vista que grupos de interesse são estabelecidos, e tem sua manutenção garantida quando as burocracias estatais assumem esses objetivos como seus. Ainda sob esse viés, pode-se entender a construção da aliança dos BRIC como um modelo de balanceamento brando, no qual se busca assegurar o 
Artigo original

Hegemonia - Revista Eletrônica de Relações Internacionais do Centro Universitário Unieuro

ISSN: 1809-1261

UNIEURO, Brasília, número 7, 2011, pp. 73-119.

desenvolvimento e sanar as vulnerabilidades que os países possam ter (HURELL, 2009).

1.3. Atores e pressões: as coalizões no tempo e espaço.

Pode-se, por um prisma sócio-histórico enxergar a questão de outra forma. Os atores são impelidos a certos constrangimentos e dinâmicas ao mesmo tempo em que eles fazem com que elas ocorram. Se por um lado as alianças estratégicas são respostas aos desafios que o sistema internacional coloca, por outro lado, os países em alianças tendem a passar por questões que sem estar na aliança passariam. Assim, tende também a existir uma pressão de grupos organizados, e uma diminuição da margem de manobra dos países conforme se configuram suas "forças profundas" e dependendo dos homens de estado e os grupos reais que os mesmos conformam (DUROSELLE, 2000). Portanto é jogado um jogo por um lado com a política doméstica, e, por outro lado, com a diplomacia (PUTNAM, 1988). Sendo assim, as alianças refletem os interesses que estão dispersos dentro e fora da nação, e não podem ser agrupados simplesmente na categoria de interesse nacional. 
Artigo original

Hegemonia - Revista Eletrônica de Relações Internacionais do Centro Universitário Unieuro

ISSN: 1809-1261

UNIEURO, Brasília, número 7, 2011, pp. 73-119.

Da mesma forma, essas ações se situam no tempo e no espaço. 0 Congresso de Viena teve grande impacto em uma política européia, em que famílias aristocráticas e setores da burguesia agiam incisivamente, e restrito ao período de 1800's. Uma visão atual baseada na época do século XIX poderia ser um sinal grave de anacronismo. Assim sendo, deve-se ter em mente que as alianças firmadas são ferramentas de negociação surgidas no limiar do século XXI, e que ainda estão por ser desenvolvidas.

Há, portanto, alto grau de indeterminação no sistema internacional e as motivações e ações nascem a partir das interações que se estabelecem entre as nações (DEVIN, 2009), sendo assim não se deve fazer um exercício de futurologia pretendendo com isso prever quais serão os resultados de tais alianças.

\section{REFERÊNCI AS BI BLI OGRÁFI CAS:}

ALMEIDA, Paulo Roberto de. "O papel dos Bric na economia mundial". In: CEBRI (org.). Comércio e negociações internacionais para jornalistas. RJ : CEBRI, 2009. 
Artigo original

Hegemonia - Revista Eletrônica de Relações Internacionais do Centro Universitário Unieuro

ISSN: 1809-1261

UNIEURO, Brasília, número 7, 2011, pp. 73-119.

AMORIM, Celso. “Multilateralismo acessório." In: DUPAS, Gilberto et alli (orgs.) A nova configuração mundial de poder. SP: Paz e Terra, 2008.

A diplomacia multilateral do Brasil - um tributo a Rui Barbosa. Brasília: FUNAG/IPRI, 2007.

ARBIX, Glauco. BRICS, the Chinese engine, and the humbling of the market fundamentalism. In: CARDIM, Carlos Henrique; MOSCARDO, Jerônimo (orgs.). III Conferência Nacional de Política Externa e Política Internacional. (RJ: Dezembro de 2008). Brasília: Fundação Alexandre de Gusmão, 2009.

BARNANÉ, I. R. "O Itamaraty e a Diplomacia Presidencial nos $\begin{array}{llll}\text { governos } & \text { FHC } & \text { Lula". }\end{array}$ www6.ufrgs.br/intrel/Artigo_Diplomacia_Presidencial.pdf (acesso 03/03/2010) 
Artigo original

Hegemonia - Revista Eletrônica de Relações Internacionais do Centro Universitário Unieuro

ISSN: 1809-1261

UNIEURO, Brasília, número 7, 2011, pp. 73-119.

BRASIL. Ministério das Relações Exteriores/ Secretaria de Planejamento Diplomático. Repertório de política externa: posições do Brasil. Brasília: Fundação Alexandre de Gusmão, 2007.

Repertório de

política externa: posições do Brasil (2008-2009). Brasília: Fundação Alexandre de Gusmão, 2010.

BULL, Hedley. A sociedade anárquica - um estudo da ordem na política mundial. Brasília: Editora Universidade de Brasília; São Paulo: Imprensa Oficial, 2002.

CERVO, Ama do Luiz. A inserção internacional: formação de conceitos brasileiros. São Paulo: Saraiva, 2008.

CEPALUNI, Gabriel; VIGEVANI, Tullo. "A política externa de Lula da Silva: a estratégia da autonomia pela diversificação." In: Contexto Internacional, vol. 29, n. 2. RJ : IRI/PUC-Rio, jul./dez. 2007. 
Artigo original

Hegemonia - Revista Eletrônica de Relações Internacionais do Centro Universitário Unieuro

ISSN: 1809-1261

UNIEURO, Brasília, número 7, 2011, pp. 73-119.

DEVIN, Guillaume. Sociologia das relações internacionais. Salvador: Editora Universidade Federal da Bahia, 2009.

DUROSELLE, Jean-Baptiste. Todo império perecerá: teoria das relações internacionais. Brasília: Editora Universidade de Brasília; São Paulo: Imprensa Oficial, 2000.

GARCIA, Eugênio Vargas. O Brasil e a Liga das Nações: Vencer ou Não Perder (1919-1926). Porto Alegre: Editora UFRGS, 2000.

GIDDENS, Anthony. As conseqüências da modernidade. São Paulo: Editora UNESP, 1991.

GILL, Stephen; LAW, David. Hegemonia global e o poder estrutural do capital. In: GILL, Stephen. Gramsci, materialismo histórico e relações internacionais. Rio de Janeiro: Ed. UFRJ, 2007.

GONÇALVES, José Botafogo. "BRIC: sigla contingente ou permanente?" In: Política Externa, Vol. 18, N. 2. São Paulo: Paz e Terra, Novembro de 2009. 
Artigo original

Hegemonia - Revista Eletrônica de Relações Internacionais do Centro Universitário Unieuro

ISSN: 1809-1261

UNIEURO, Brasília, número 7, 2011, pp. 73-119.

. “BRICs Cooperação em comércio e indústria. Um ponto de vista do lado brasileiro.". In: Mural Internacional. Ano 1 n.1. Rio de Janeiro: PPGRI/UERJ, jan/jun.2010.

GREGORY, Denise. "O Brasil entre os emergentes e a internacionalização das empresas brasileiras". In: CEBRI (org.). Comércio e negociações internacionais para jornalistas. Rio de Janeiro: CEBRI, 2009.

GUEDES, Luisa. "Aspectos da busca do Brasil por um assento permanente no Conselho de Segurança da ONU nos governos Cardoso e Lula." In: II Simpósio de Pós-Graduação em Relações Internacionais do Programa "San Tiago Dantas" (UNESP, UNICAMP, PUC/SP). Novembro de 2009.

GUIMARÃES, Samuel Pinheiro. Palestra do Senhor Secretário-Geral das Relações Exteriores. In: CARDIM, Carlos Henrique; MOSCARDO, Jerônimo (orgs.). III Conferência Nacional de Política Externa e 
Artigo original

Hegemonia - Revista Eletrônica de Relações Internacionais do Centro Universitário Unieuro

ISSN: 1809-1261

UNIEURO, Brasília, número 7, 2011, pp. 73-119.

Política Internacional. (RJ: Dezembro de 2008). Brasília: Fundação Alexandre de Gusmão, 2009.

HIRST, Mônica; LIMA, Maria Regina Soares de. "Brasil como país intermediário e poder regional" In: HURRELL, Andrew et al. (orgs.) Os Brics e a Ordem Global. Rio de Janeiro: Editora FGV, 2009.

HURELL, Andrew. “Hegemonia, liberalismo e ordem global: qual o espaço para potências emergentes?" In: HURRELL, Andrew et al. (orgs.) Os Brics e a Ordem Global. Rio de Janeiro: Editora FGV, 2009.

LÉVY, Pierre. Cibercultura. São Paulo: Editora 34, 1999.

LESSA, Mônica Leite. "A política cultural brasileira e a sociedade das nações". RJ : Sociedade Brasileira de Pesquisa Histórica; Anais da XXII Reunião, p. 89-97; 2002.

LESSA, Carlos; PADULA, Raphael; SANTOS, Gustavo. "Considerações sobre energia e logística no Brasil.". MAGALHÃES, João Paulo (org.) 
Artigo original

Hegemonia - Revista Eletrônica de Relações Internacionais do Centro Universitário Unieuro

ISSN: 1809-1261

UNIEURO, Brasília, número 7, 2011, pp. 73-119.

Os anos Lula - contribuições para um balanço crítico (2003-2010). Pg. 209-229. Rio de Janeiro: Garamond, 2010.

LIMA, Maria Regina Soares de. “A politização da política externa e os interesses nacionais."

In:

http://www.global21.com. br/materias/materia. asp?cod=25102\&tipo=notici

a (acesso: 12/12/2009)

. “Instituições Democráticas e Política

Exterior". Contexto Internacional vol.22 n.2. Rio de Janeiro, IRI/PUCRj, jul./dez.2000. p.265-303.

MIHAILOVIC, Dejan. “Geopolítica y orden global: posibilidades para un nuevo meridionalismo." In: Revista Razón y Palabra, Número 62. ISSN $1605-4806$.

http://www.razonypalabra.org.mx/n62/dmihailovic.html (01/11/2009). 
Artigo original

Hegemonia - Revista Eletrônica de Relações Internacionais do Centro Universitário Unieuro

ISSN: 1809-1261

UNIEURO, Brasília, número 7, 2011, pp. 73-119.

MI LANI, Carlos R. S.. O Anti/Alterglobalismo e o Fórum Social Mundial de Nairóbi: Contestação e redes transnacionais na política mundial. In: Cena Internacional, Vol. 9, N.1, páginas 102 a 122, 1오 semestre de 2007, Brasília: IREL, 2007.

MILLER, Darlene. "A África do Sul e o IBSA: Constrangimentos e Desafios". In: Cena Internacional, ano 6, n. 2, Brasília: IREL/UNB, 2004. p. $160-180$

OLIVEIRA, Marcelo Fernandes de. "Alianças e coalizões internacionais do governo Lula: o IBAS e o G-20." In: Brasília: Revista Brasileira de Política Internacional. 8 (2). p. 55-69. 2005.

OLIVEIRA, Amâncio Jorge; PFEIFER, Alberto. "O empresariado e a política exterior do Brasil." In: ALTEMANI, H.; LESSA, A.C. (orgs.), Relações Internacionais do Brasil. Temas e agendas. Volume 2. São Paulo: Editora Saraiva, 2006.

PECEQUILO, Cristina Soreanu. "A política externa do Brasil no século XXI: os eixos combinados de cooperação horizontal e vertical." 
Artigo original

Hegemonia - Revista Eletrônica de Relações Internacionais do Centro Universitário Unieuro

ISSN: 1809-1261

UNIEURO, Brasília, número 7, 2011, pp. 73-119.

Brasília: Revista Brasileira de Política Internacional. N. 51 (2), p. 136153; 2008.

PINHEI RO, Letícia. Política externa brasileira. RJ: Jorge Zahar Editor, 2004.

PUTNAM, Robert D. "Diplomacy and Domestic Politics: The Logic of Two-Level Games". In: International Organization, 42 (Summer 1988), pp. 427-460.

SARAIVA, Miriam Gomes. "As estratégias de cooperação Sul-Sul nos marcos da política externa brasileira de1993 a 2007". Brasília: Revista Brasileira de Política Internacional, ano 50, n.2. IBRI, 2007. p.42-59.

SATO, Eiiti. "De Gatt para OMC e a agenda do Brasil no comércio internacional." In: ALTEMANI, H.; LESSA, A.C. (orgs.), Relações Internacionais do Brasil. Temas e agendas. Volume 2. São Paulo: Editora Saraiva, 2006. 
Artigo original

Hegemonia - Revista Eletrônica de Relações Internacionais do Centro Universitário Unieuro

ISSN: 1809-1261

UNIEURO, Brasília, número 7, 2011, pp. 73-119.

TAVARES, Maria da Conceição. A crise financeira atual. In: CARDIM, Carlos Henrique; MOSCARDO, Jerônimo (orgs.). Crise Financeira. Textos acadêmicos. (RJ: Maio de 2009). Brasília: Fundação Alexandre de Gusmão, 2009.

VARGAS, João A. C. "Persuadir e legitimar: a argumentação brasileira em favor da reforma do Conselho de Segurança." In: Cena Internacional, Volume 10, Número 2, Brasília: IREL/UNB, 2008. p. 119-138.

VIZENTINI, Paulo Fagundes. "O G-3 e o G-20: o Brasil e as novas coalizões internacionais." In: ALTEMANI, H.; LESSA, A.C. (orgs.), Relações Internacionais do Brasil. Temas e agendas. Volume 2. São Paulo: Editora Saraiva, 2006.

ZORGBIBE, Charles. O pós-guerra fria no mundo. SP: Papirus, 1996. 